\title{
Inferential Processes in the Forced Compliance Situation
}

\section{A Bayesian Analysis ${ }^{1}$}

\author{
YAACOV TROPE: \\ The University of Michigan
}

\begin{abstract}
The attribution made by an observer $(O)$ to an actor in the forced compliance situation was regarded as a probability revision process which can be described by a Bayesian inference model. Os' perceptions of the forced compliance situation were analyzed in terms of the input components into the Bayesian model: prior probabilities of the relevant attitudes and the diagnostic values of the behaviors which the actor may choose. In order to test propositions made by attribution theory about such perceptions (Kelley, 1967; Messick, 1971), Os viewed actors under conditions of Low Inducement (LI) and High Inducement (HI). Before observing the actor's decision, $O_{s}$ estimated the prior probabilities of the relevant attitudes and the conditional probabilities of compliance and refusal given each of the attitudes. After observing the actor's decision, $O s$ estimated the posterior probabilities of the attitudes. As expected, in the LI condition, compared to the HI condition, compliance was seen as less probable and more diagnostic about the actor's attitudes, and the posterior probability of the corresponding attitude was higher. Contrary to expectations, within both conditions, compliance, compared to refusal, was seen as less diagnostic and more probable.
\end{abstract}

Attribution theory has been reformulated recently in terms of subjective probability revision by Ajzen (1971) and by Messick (1971). The present study elaborates on Ajzen's and Messick's approach and uses it to predict observers' inferences about an actor in the forced compliance situation.

Attribution theory makes the important assertion that the degree of certainty in inferring underlying traits from behavior is inversely related

${ }^{1}$ This research was supported by a grant from the National Institute of Mental Health (MH-16950-04). The author is grateful to E. Burnstein, R. Zajonc, A. Vinokur, and L. van Rooijen for valuable comments on the manuscript.

${ }^{2}$ Correspondence regarding this manuscript should be addressed to the author at the Institute for Social Research, The University of Michigan, Ann Arbor, MI 48106.

I

Copyright (C) 1974, by Academic Press, Inc.

All rights of reproduction in any form reserved. 
to the behavior's subjective prior probability. This relationship between the likelihood of an act and inference of traits was first suggested by Heider (1958, p. 169). More recently, Jones and Gerard (1967, p. 264) derived the same proposition from the assumption that the informational value of a behavior is determined by the amount of uncertainty reduced by its occurrence. Indeed, in information theory the amount of uncertainty reduced by a single event is inversely related to its prior probability. Kelley (1967) arrived at a similar conclusion in his discussion of the consensus criterion in person perception, that is, an observer will take an actor's behavior as a reliable reflection of the latter's trait to the extent that his behavior deviates from what most people would do in that situation. Ajzen (1971) provided direct empirical support for these notions by obtaining negative correlations between prior behavior probabilities and measures of trait inference.

Prior behavior probability is not necessarily the sole determinant of trait inference. One can conceive of different situations having the same prior behavior probabilities but differing in the number of perceived traits causing the behavior or in the degree to which the behavior is perceived as equally likely under the various causes. Such situations differ, therefore, in the diagnustic value of behavior, i.e., the extent to which the behavior is uniquely associated with one of the causes. The diagnostic value of a behavior should, in turn, be positively related to the certainty with which a trait is inferred. Similar conclusions are implied in Kelley's (1971) contention that a given cause will be inferred with relatively little certainty when a behavior is perceived to have multiple plausible causes. Equivalently, Jones and Davis (1965) argued that the smaller the overlap between the possible causes of behavior and those of other behaviors, and the smaller the number of causes unique to a behavior, the higher the confidence in inferring a given cause. Finally, Ajzen (1971) has drawn attention to the constraining role of the prior probability of a trait. That is, confidence in a trait after observing behavior is positively related to amount of confidence in the trait before observing the behavior.

These considerations imply that trait attribution can be regarded as a product of a rational inferential process. Indeed, Kelley (1971) stated: "It is proposed that our theory of attribution must be grounded in a view of the layman as an applied scientist." This suggests that a normative model such as Bayesian inference theory (Edwards, Lindman, and Phillips, 1965) might serve fruitfully as a model of the trait inference process. In the discrete Bayes' model, we let $\mathrm{P}\left(\mathrm{T}_{i}\right)$ denote the prior probability of a trait belonging to a mutually exclusive and exhaustive set of 
traits, $T_{1}, \ldots, T_{i}, \ldots, T_{n}$, and let $P\left(B_{j}\right)$ denote the prior probabilities of a behavior belonging to a mutually exclusive and exhaustive set of behaviors, $B_{1}, \ldots, B_{j}, \ldots, B_{m}$. The behaviors are linked to the traits through $P\left(B_{j} \mid T_{1}\right)$ 's which specify the conditional probability of $B_{j}$ given $T_{i}$. Finally, if $P\left(T_{i} \mid B_{j}\right)$ denotes the probability of $T_{i}$ contingent on observing $B_{j}$. Bayes' theorem states that

$$
P\left(T_{i} \mid B_{j}\right)=\frac{P\left(T_{i}\right) P\left(B_{j} \mid T_{i}\right)}{P\left(B_{j}\right)},
$$

where

$$
P\left(B_{j}\right)=\sum_{i=1}^{n} P\left(T_{i}\right) P\left(B_{j} \mid T_{i}\right), \quad \text { and } \quad \sum_{j=1}^{m} P\left(B_{j} \mid T_{i}\right)=1.0 .
$$

For a set including two traits, $T_{1}$ and $T_{2}$, equation (1) can be expressed for $T_{1}$ and $T_{2}$, respectively. Then, division of equation (1) for $T_{1}$ by the same equation in terms of $T_{2}$ yields:

$$
\frac{P\left(T_{1} \mid B_{j}\right)}{P\left(T_{2} \mid B_{j}\right)}=\frac{P\left(T_{1}\right) P\left(B_{j} \mid T_{1}\right)}{P\left(T_{2}\right) P\left(B_{j} \mid T_{2}\right)}
$$

Equation (2) can be stated more simply as

$$
\Omega_{1}=\Omega_{0} L R\left(B_{j}\right),
$$

where

$$
\Omega_{0}=\frac{P\left(T_{1}\right)}{P\left(T_{2}\right)}
$$

is the subjective odds in favor of $T_{1}$ prior to observing $B_{j}$,

$$
\Omega_{1}=\frac{P\left(T_{1} \mid B_{j}\right)}{P\left(T_{2} \mid B_{j}\right)}
$$

is the odds posterior to observing $B_{j}$, and

$$
\operatorname{LR}\left(B_{j}\right)=\frac{P\left(B_{j} \mid T_{1}\right)}{P\left(B_{j} \mid T_{2}\right)}
$$

is the likelihood ratio of the two conditional probabilities associated with $\mathbf{B}_{j}$. Taking logarithms in Equation (3), we have the following additive inference model:

$$
\log \Omega_{1}=\log \Omega_{0}+\log L R\left(B_{j}\right) .
$$

It can be seen that the model incorporates quantitatively the considera-

In this paper such concepts as probability, likelihood, likelihood ratio, and odds will stand for their respective subjective counterparts from the observer's point of view. 
tions specified by attribution theory in its analysis of trait inference, to wit: posterior trait probability is inversely related to prior behavior probability; the impact of observed behavior depends on the degree to which it distinguishes between the possible traits, i.e., its diagnostic value $\operatorname{LR}\left(B_{j}\right)$; and the posterior trait probability depends on its prior probability.

The fit between observers' trait inferences and those predicted by Bayes' theorem which was reported by Ajzen (1971) as well as a theoretical analysis by Messick (1971) have already demonstrated the model's usefulness. For our purposes, Messick's (1971) discussion of the asymmetric certainty principle is of particular interest. Suppose an observer considers two equally likely traits, $T_{1}$ and $T_{2}$, and two behaviors, $B_{1}$ and $B_{2}$, which are behavioral manifestations of $T_{1}$ and $T_{2}$, respectively. It is assumed that $\mathrm{P}\left(\mathrm{B}_{1} \mid \mathrm{T}_{1}\right)$ approaches certainty, i.e., it is close to unity, and that $\mathrm{P}\left(\mathrm{B}_{1} \mid \mathrm{T}_{2}\right)=\mathrm{S}$. Since

$$
\sum_{j=1}^{2} P\left(B_{j} \mid T_{i}\right)=1,
$$

$P\left(B_{2} \mid T_{1}\right)$ is close to zero, and $P\left(B_{2} \mid T_{2}\right)=1-S$. Fig. 1, adapted with some modifications from Messick (1971), illustrates the stochastic relations involved.

If $B_{1}$ occurs, the posterior odds in favor of $T_{1}$ equal $1.0 / S$, i.e., $B_{1}$ does not lead to a certain inference. If $\mathrm{B}_{2}$ occurs, however, the posterior odds in favor of $T_{2}$ equal $(1-S) / 0$ (infinity), i.e., $T_{2}$ is inferred with certainty. Messick suggested that these stochastic contingencies are an idealized model of attribution processes in several experiments on trait inference. In such experiments, the situation from the observer's point of view is structured so that there is an external pressure on the actor to choose, say, $B_{1}$ rather than B.2 (e.g., Jones, Davis, \& Gergen, 1961). Be-

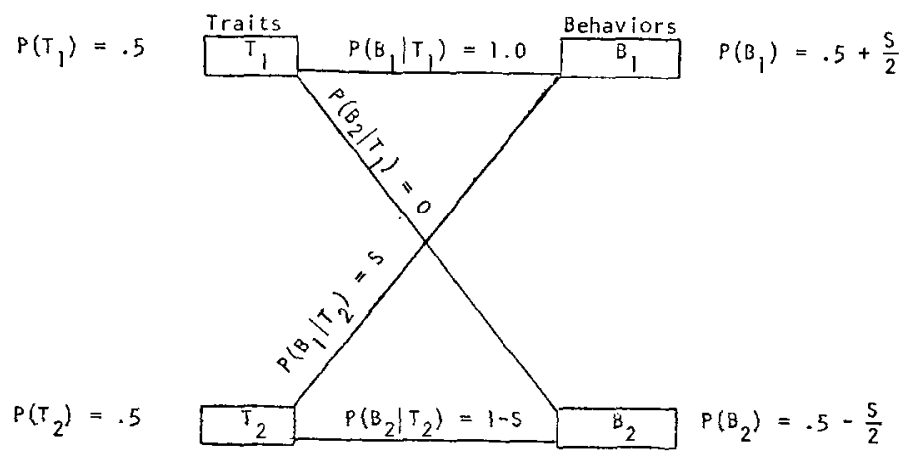

FIG. 1. Graphical illustration of the asymmetric certainty principle. 
cause of the situational pressure, $B_{1}$ may be produced both by actors possessing $T_{1}$ and by actors possessing $T_{2}$. In the first case, there is no reason why a person possessing the trait $T_{1}$ (which is congruent with behavior $B_{1}$ ) and who is under pressure to behave so will not produce $B_{1}$, i.e., $P\left(B_{1} \mid T_{1}\right)$ $=1.0$. In the second case, because of the external pressure, there is some probability, $\mathrm{P}\left(\mathrm{B}_{1} \mid \mathrm{T}_{2}\right)=\mathrm{S}$, that a person possessing $\mathrm{T}_{2}$ will inaccurately present himself by $\mathrm{B}_{1}$. The occurrence of $\mathrm{B}_{1}$ (e.g., "in-role" behavior) therefore leaves it ambiguous as to whether the actor possesses $T_{1}$ to $T_{2}$. The occurrence of $\mathrm{B}_{2}$ (e.g., "out-of-role" behavior) can be explained only by invoking $T_{2}$, since the subjective probability that it was produced by an actor possessing $T_{1}$ is close to zero. In other words, the diagnostic value of $B_{2}$ is higher than that of $B_{1}$.

The "interpersonal simulation" of the forced compliance paradigm (Bem, 1972) is one of the trait inference situations which has attracted much attention in recent years. The present study makes use of the same paradigm. In this case, observers' $\left(O s^{\prime}\right)$ inferences will be analyzed in terms of the theoretical notions developed in the preceding discussion.

For our purposes we will assume that, for example, in Bem's (1965) "interpersonal simulation" of Cohen's (1962) study Os had to infer whether the actor is in favor $\left(\mathrm{T}_{1}\right.$, pro) or against $\left(\mathrm{T}_{2}\right.$, anti) police intervention on campus. We will also assume that he considers two possible behaviors: compliance $\left(B_{1}\right)$ and refusal $\left(B_{2}\right)$ with the experimenter's request to take a pro position. The question is what a priori probabilistic structure simulates $O s^{\prime}$ perception of the forced compliance situation. Kelley's (1967) attributional analysis of the forced compliance situation employed by Festinger and Carlsmith (1959) is relevant here. Kelley argued that $O s^{\prime}$ judgment of an inverse relation between inducement magnitude and attitude inference "is probably associated with assumptions (unchecked in Bem's work, as far as 1 know) that there is a distribution of opinion toward the task, and only the more favorable subjects complied in the $\$ 1$ case and almost all, favorable or not, complied in the $\$ 20$ case" (Kelley, 1967, p. 226). Consider the implications of this argument for the High Inducement $(\mathrm{HI})$ condition. First, $\mathrm{P}\left(\mathrm{B}_{1}\right)>$ $\mathrm{P}\left(\mathrm{B}_{2}\right)$, as in Fig. 1. Second, the assumption that $O$ s expect both pro and anti actors to comply implies that both $\mathrm{P}\left(\mathrm{B}_{1} \mid \mathrm{T}_{1}\right)$ and $\mathrm{P}\left(\mathrm{B}_{1} \mid \mathrm{T}_{2}\right)$ are high. The former is probably close to unity and higher than the latter which can be assumed to equal $S$. It follows that $P\left(B_{3} \mid T_{T}\right)$ is near zero and that $\mathrm{P}\left(\mathrm{B}_{2} \mid \mathrm{T}_{2}\right)=1-\mathrm{S}$. Thus, excluding the prior trait probability distribution, which is probably biased in favor of $T_{2}$, all these likelihoods are represented in Fig. 1. Thus, according to this analysis, the HI condition can be regarded as a situation of asymmetric certainty. As to the Low Inducement (LI) condition, Kelley's analysis seems to imply that, due 
to the absence of salient external pressure, actors are expected to behave more in keeping with their attitudes, that is, both $P\left(B_{1} \mid T_{1}\right)$ and $\mathrm{P}\left(\mathrm{B}_{2} \mid \mathrm{T}_{2}\right)$ are high. This proposition in conjunction with the assumption that $\mathrm{P}\left(\mathrm{T}_{1}\right)<\mathrm{P}\left(\mathrm{T}_{2}\right)$ imply that in the $\mathrm{LI}$ condition $\mathrm{P}\left(\mathrm{B}_{1}\right)<\mathrm{P}\left(\mathrm{B}_{2}\right)$, i.e., only few actors are expected to comply.

To summarize, the preceding analysis suggests that in the LI condition, compared to the HI condition, compliance has a lower prior probability and a higher diagnostic value. Therefore, compliance should produce a higher posterior probability of the corresponding attitude in the LI than in the HI condition. Furthermore, according to the analysis, within the HI condition, higher prior probability and a lower diagnostic value are associated with compliance than with refusal; within the LI condition, the prior probability of compliance is lower than that of refusal, but refusal and compliance do not differ in diagnostic value.

The present study will subject these propositions to direct test by obtaining from $O_{\mathrm{s}}$, before they observe the actor's choice, the likelihoods which serve as input into the Bayesian model. Attitude inference will be assessed by obtaining from $O$ s attitude probabilities, after they observe the actor's choice.

\section{METHOD}

Observers. Sixty-four undergraduates at The University of Michigan, all drawn from the psychology subject pool, served as observers. Participation in the experiment fulfilled a course requirement.

Design. Os were exposed to either a HI or a LI procedure. Within each inducement condition, each of four groups of $O_{s}$ viewed one of four different actors. Thus, $a 2 \times 4$ nested classification design was formed with actors nested within inducement magnitude levels. Eight $O s$ were randomly assigned to each of the eight experimental conditions.

Procedure. $\mathrm{O}_{\mathrm{s}}$, in groups of eight, were given the following instructions:

This study is designed to determine how accurately people can judge another person on the basis of his behavior. You will receive a description of an experiment which took place in this laboratory and in which student $K$ participated. The description will be divided into two parts. The first will be a written one and the second will be a recorded video tape film. Some of the judgments you will be asked to make will be in the form of probability estimates which will be compared to those given by a mathematical equation. We will start, therefore, with a practice problem in order to familiarize you with such estimates.

As practice the "book bags and poker chips" problem was used (see Peterson \& Miller, 1965). Following information about the number and composition of each type of bag, but before knowing the result of a simulated draw, $O$ s were asked to estimate the prior probabilities of each type of bag and the conditional probabilities of each kind of chip given the various types of bags. At this point, $O$ s were given explanations of the meaning of probability estimation and were encouraged to ask 
questions. After the result of the simulated draw had been told, Os were asked to estimate posterior probabilities of each type of bag.

An experiment, similar in general outline to that reported by Helmreich and Collins (1968), was then described. Os received a booklet beginning with a description of student $K$ who belonged to the subject pool and who was called to the lab in order to fill out a self report personality questionnaire (Rotter's, 1966 I-E scale). The booklet continued with the procedure Helmreich and Collins used to administer the questionnaire and to explain its nature. Os then read in the description that $E$ added:

"It is our routine to ask for subjects' consent to take questionnaires which include questions about various aspects of their personality. Are you willing to answer this questionnaire?"

The text indicated that $\mathrm{K}$ agreed and that he worked on the questionnaire for 15 minutes. Os were asked to read the questionnaire which was given in the next page in the booklet. The text then continued as follows:

After $\mathrm{K}$ completed the questionnaire, the experimenter thanked him for participating in the research and added:

"I would like you to fill out the 'Subject's Rcport on Psychology Expcriments' questionnaire which is administered to all subjects participating in psychological experiments in order to get their reactions to and evaluations of the experiments. (Note. This questionnaire is given in the next page. From the description you were given, estimate as well as you can K's reactions to and evaluations of the experiment.)"

The items in the questionnaire were applicable to any psychology experiment. Anong fill in items, two dealt with perceived freedom. The first asked: "How much choice do you feel you had to turn down the experimenter's request to perform the experimental task?" The second asked: "If you were asked about your opinions, how much freedom do you feel you had to express your true opinions?" A 7-point scale accompanied both questions. Both scales ranged from absolutely no choice to absolute freedom of choice.

Another question asked for estimates of prior probabilities of agreeing and refusing to perform the tasks. "Imagine 100 typical students in this situation, how many do you think would agree to do the task you just did and how many would refuse? In front of each of these alternatives below, place the number of students who would choose it. Please make sure that your estimates sum to 100 , so that you have accounted for all 100 students.

students out of 100 typical students would agree. students out of 100 typical students would refuse."

The text then continued as follows:

While $\mathrm{K}$ worked on this questionnaire another experimenter entered the room and said that he would like to talk to the subject for a moment after he finished. When $\mathrm{K}$ completed the questionnaire he followed the second experimenter to another room. (Note. From this point the procedure was recorded and it will be shown to you on this monitor.)

Each of the eight groups of $O_{s}$ viewed a different video tape. These video tapes 
were obtained in a previous study (Trope, 1971) in which actual inducement to and performance of a counter attitudinal behavior was recorded. All tapes were of male subjects. Special care was taken to assure that the tapes were similar in such characteristics as length and quality of the counter attitudinal behavior, amount of willingness expressed in compliance, and technical quality of the recording.

The video tape showed $E$ and $\mathrm{K}$ entering the room and $E$ was heard saying: "I am preparing materials to be used in research with an experimental section of a psychology class which meets in an electronically equipped classroom, and I need your help for a few minutes. The research is on attitude change, and a number of communications will be presented to the students to see if their opinions can be altered. I would like you to make a video tape forcefully stating arguments in favor of keeping intelligence files on potentially subversive students. I prepared four general arguments in favor of keeping files on potentially subversive students, and you can add more arguments. You simply have to state your name, home town, class, and major, and present the arguments. We are interested in the long term effects of a communication on attitudes. So, we plan to measure their attitude right after we play the tape and again at the end of the semester. Because of this, it is extremely important that you not tell anyone what you really think about the issue or why you made the tape before the end of the semester."

In the LI condition, $E$ continued: "Since you just finished an experiment, you completed the subject pool requirements for today, and it is up to you whether to do it or not. Can you help us out?"

In the HI condition, the $E$ continued: "Since the experiment you just finished took only 15 minutes, and you were called for an hour, your subject pool requirements for today may be considered incomplete if you do not participate in this research. But it is up to you whether you do it or not. Can you help us out?"

The replay was stopped at this point, prior to K's answer. Os returned to the text and answered the questions asking for estimates of the prior probabilities which constitute the input to Bayes' formula. The general format of these questions was similar to that used by Ajzen (1971). The first question asked for prior trait probabilities $\mathrm{P}\left(\mathrm{T}_{\mathrm{i}}\right)$. "Out of 100 typical students, how many do you think are in favor of keeping intelligence files on potentially subversive students, and how many are against keeping files on potentially subversive students? Place your estimates in the appropriate spaces below. Please make sure that your estimates sum to 100 so that you have accounted for all 100 students.

Out of 100 typical students, students are in favor of keeping files on potentially subversive students, and files on potentially subversive students."

The second and third questions asked for prior conditional probabilities, $P\left(B_{j} \mid T_{1}\right)$ and $\mathrm{P}\left(\mathrm{B}_{\mathbf{j}} \mid \mathbf{T}_{2}\right)$, respectively. The second question asked: "Out of 100 students who are in favor of keeping files on potentially subversive students, how many do you think would agree in this situation to make the video tape presentation and how many would refuse? In front of each alternative below, place the number of these students who would choose the alterantive in this situation. Please make sure that your estimates sum to 100 , so that you have accounted for all 100 students.

Out of 100 students who are in favor of keeping files on potentially subversive students, __ students would agree, and students would refuse." 
The third question was identical to the second except that "in favor" was replaced by "against."

After $O_{s}$ had completed these questions, the video tape replay continued. $\mathrm{K}$ was seen agreeing to make the presentation, preparing it, and then presenting it. Following the presentation, $O$ s refurned to the text where they answered the question asking for estimates of posterior trait probability, $P\left(T_{i} \mid B_{1}\right)$. "In view of his choice, what are the chances that $\mathrm{K}$ is in favor of or against keeping intelligence files on potentially subversive students? Choose numbers between 0 and 100 to represent how likely you think it is that $\mathrm{K}$ is in favor of or against keeping files on potentially subversive students. Place your estimates in the appropriate spaces below. Again, please make sure that your estimates sum to 100 .

The chances are - in 100 that $\mathrm{K}$ is in favor of keeping files on potentially subversive students, and - in 100 that $K$ is against keeping files on potentially subversive students."

$O S$ then continued reading the text. They were told that $E$ gave $K$ a questionnaire which he intended to use in his study and asked him to fill it out so that he could see how long it takes, get suggestions for improvement, and know how $\mathrm{K}$ feels about the issue. In addition to questions asking for cvaluations of the presentation, the questionnaire included the following item: "Intelligence files should be kept on potentially subversive students." A 7-point scale ranging from strongly disagree to strongly agree followed this statement. Os were given the questionnaire and were asked to indicate in it their estimates of K's opinion. Finally, Os were told that $E$ asked $\mathrm{K}$ to fill out the 'Subject Report on Psychology Experiments' questionnaire. Os were asked again to estimate $\mathrm{K}$ 's reactions to and evaluations of the task he performed with the second $E$.

\section{RESULTS}

\section{Subjective Prior Probabilities}

The relevant variables for the analysis of $O$ 's perception of the forced compliance situation, prior to observing the compliant act, were based on the input components into Bayes' theorem, i.e., subjective prior trait (attitude) probabilities, $\mathrm{P}\left(\mathrm{T}_{\mathrm{i}}\right)$, and subjective conditional behavior probabilities, $P\left(B_{j} \mid T_{i}\right)$. The first six columns in Table 1 present the means of these probabilities and of several indices derived from Bayes' theorem which manipulate these probabilities. (These indices are described below.) Also presented are $F$ ratios for the main effects of inducement magnitude obtained from two-way analyses of variance in which inducement magnitude and actors (nested within inducement magnitude levels) served as factors. ${ }^{4}$

'In all analyses of variance, the main effect of actors did not reach the .25 level of significance. Therefore, the actors and the within cell mean squares were pooled to provide a single residual term. Since actors are nested within inducement magnitude levels, there is no interaction term, so that only one $F$ ratio is reported. 


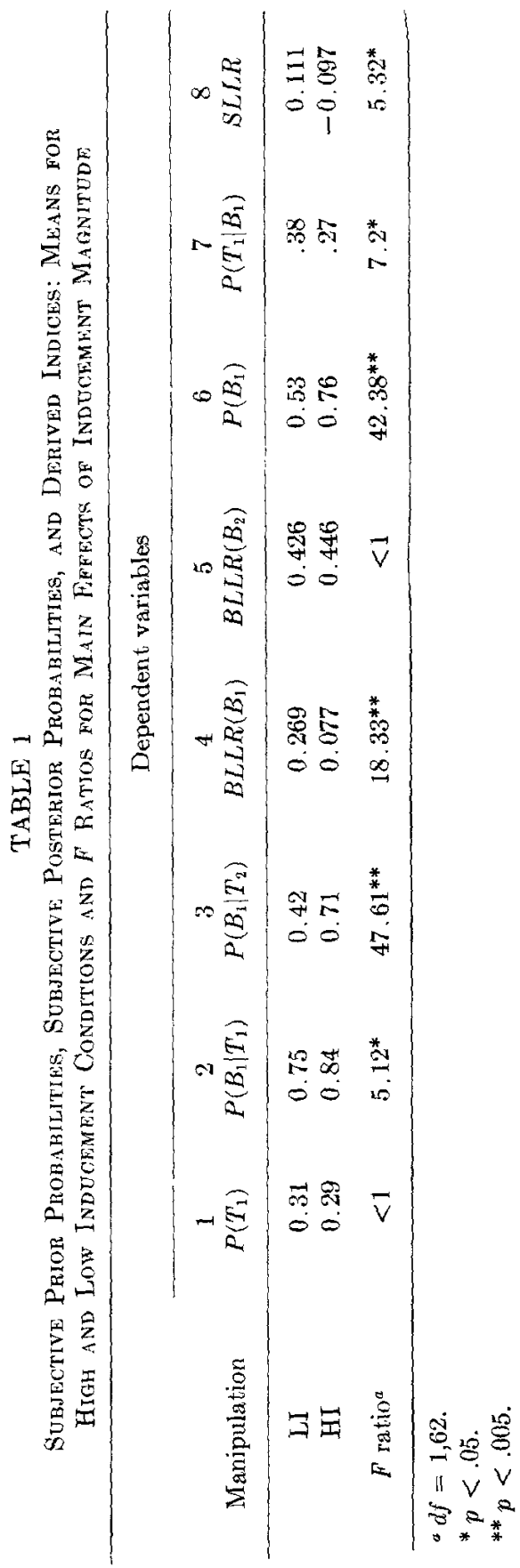


Column 1 in Table 1 gives the probability of an attilude in favor of keeping files on potentially subversive students, $\mathrm{P}\left(\mathrm{T}_{1}\right)$. The probability of an attitude against keeping files on potentially subversive students, $\mathrm{P}\left(\mathrm{T}_{2}\right)$, is the complement of $\mathrm{P}\left(\mathrm{T}_{1}\right)$. It appears that the prior probability distribution over attitudes was biased in favor of $T_{2}$ and that the LI and HI conditions did not differ in this respect.

As expected, $P\left(B_{1} \mid T_{1}\right)$, the probability that students in favor of files will comply (Column 2), was rather high in both inducement conditions. It was significantly higher, however, in the HI than in the LI condition. Column 3, contrary to expectations, revcals that even in the LI condition a considerable proportion of the students who oppose files are expected to comply. A comparison between columns 2 and 3 suggests that the difference between the two experimental conditions was more pronounced for the behavior probabilities conditional on $T_{2}$ (i.e., on the probabilities of compliance and refusal by students who are against files, $P\left(B_{1} \mid T_{2}\right)$ and $P\left(B_{2} \mid T_{2}\right)$, respectively) than for the corresponding behavior probabilities conditional on $T_{1}$ (i.e., $P\left(B_{1} \mid T_{1}\right)$ and $P\left(B_{2} \mid T_{1}\right)$, respectively). Thus, $\mathrm{P}\left(\mathrm{B}_{1} \mid \mathrm{T}_{2}\right)<\mathrm{P}\left(\mathrm{B}_{2} \mid \mathrm{T}_{2}\right)$ in the $L I$ condition while the opposite holds for the HI condition. On the other hand, $P\left(B_{1} \mid T_{1}\right)>$ $\mathrm{P}\left(\mathrm{B}_{2} \mid \mathrm{T}_{1}\right)$ in both the $\mathrm{LI}$ and $\mathrm{HI}$ conditions. To explore further these results, a three-way analysis of variance was conducted with the likelihoods $P\left(B_{1} \mid T_{1}\right)$ and $P\left(B_{1} \mid T_{2}\right)$ as a within $S s$ factor, in addition to the factors of inducement magnitude and actors. A significant interaction between inducement magnitude and type of likelihood was obtained $(F(1,62)=13.96, p<.005)$. This result reflected the larger difference between the two experimental conditions on $\mathrm{P}\left(\mathrm{B}_{1} \mid \mathrm{T}_{2}\right)$ than on $\mathrm{P}\left(\mathrm{B}_{1} \mid \mathrm{T}_{1}\right)$. The same results would have been obtained, of course, with $P\left(B_{2} \mid T_{1}\right)$ and $\mathrm{P}\left(\mathrm{B}_{2} \mid \mathrm{T}_{2}\right)$.

From the likelihoods given by $O_{s}$, Bayesian log likelihood ratios associated with compliance and refusal were computed for each $O$ as follows:

$$
B L L R\left(B_{1}\right)=\log \left(\frac{P\left(B_{1} \mid T_{1}\right)}{P\left(B_{1} \mid T_{2}\right)}\right) \text { and } B L L R\left(B_{2}\right)=\log \left(\frac{P\left(B_{2} \mid T_{2}\right)}{P\left(B_{2} \mid T_{1}\right)}\right)
$$

respectively. $\operatorname{BLLR}\left(B_{j}\right)$ represents the impact a given behavior should have on the prior odds, i.e., the perceived diagnostic value of a given behavior. As predicted, the diagnostic value of compliance (Table 1, column 4) was higher in the LI than in the HI condition. Column 5 indicates that the experimental conditions did not differ in the diagnostic value of refusal. It was also hypothesized that within the $\mathrm{HI}$ condition the diagnostic value of refusal will be higher than that of compliance and that within the LI condition compliance and refusal will have similar diagnostic values. The results in columns 5 and 6 lend support to the 
first part of the prediction but disconfirm the second. More specifically, in both conditions refusal was more diagnostic than compliance. (In the HI condition, $t(31)=6.1, p<.005$; in the LI condition, $t(31)=3.82$, $p<.005$.)

With regard to prior behavior probabilities, it was predicted that the prior probability of compliance, $\mathrm{P}\left(\mathrm{B}_{1}\right)$, will be higher in the $\mathrm{HI}$ than in the LI condition. This probability was estimated as follows:

$$
P\left(B_{1}\right)=\sum_{i=1}^{2} P\left(T_{i}\right) P\left(B_{1} \mid T_{i}\right) .
$$

The data in Table 1, column 6 strongly confirm this hypothesis. However, the hypothesis that $\mathrm{P}\left(\mathrm{B}_{1}\right)>\mathrm{P}\left(\mathrm{B}_{2}\right)$ in the $\mathrm{HI}$ condition and that $\mathrm{P}\left(\mathrm{B}_{1}\right)<\mathrm{P}\left(\mathrm{B}_{2}\right)$ in the $\mathrm{LI}$ condition was only partially supported. In both conditions $\mathrm{P}\left(\mathrm{B}_{1}\right)>\mathrm{P}\left(\mathrm{B}_{2}\right)$ (but $\mathrm{P}\left(\mathrm{B}_{1}\right)$ was significantly greater than 0.5 only in the HI condition). (In the HI condition $t=10.6, p<$ .005 ; in the LI condition $t=1.4$.)

\section{Subjective Posterior Probabilities}

Column 7 in Table 1 presents the posterior trait probability that the actor is in favor of keeping files, $P\left(T_{1} \mid B_{1}\right)$. As expected, following observation of compliance, the posterior probability of the corresponding attitude was higher in the LI condition than in the HI condition. In both conditions, however, this probability did not exceed .5. In other words, observers believed that it is more likely that the actor was "drawn" from the population which opposes keeping files than from the population which favors files.

From $O$ 's posterior trait probabilities, posterior odds were computed, i.e., $\Omega_{1}=\mathrm{P}\left(\mathrm{T}_{1} \mid \mathrm{B}_{1}\right) / \mathrm{P}\left(\mathrm{T}_{2} \mid \mathrm{B}_{1}\right)$. The $\log$ of these posterior odds, $\log \Omega_{1}$, and the $\log$ of the prior odds, $\log \Omega_{0}$, were used to obtain a subjective log likelihood ratio for each $O$ as follows: SLLR $=\log \Omega_{1}-\log \Omega_{0}$. SLLR represents the actual impact of observed behavior on the O's prior opinion; it is a function of the ratio by which the prior odds were actually revised into posterior odds (Phillips \& Edwards, 1966). Mean values of SLLR are presented in column 8. It is apparent that the actual revision of opinion in light of compliance was more pronounced in the LI than in the HI condition. In order to test the usefulness of Bayes' theorem as a descriptive model, the correlation between SLLR and BLLR was computed. Recall that BLLR is the diagnostic value which Os assign to the behavior; therefore, it represents the diagnostic impact that should be associated with observation of the behavior. This correlation reflects then the degree to which the impact of observed behavior on O's prior opinions fits the 
impact the bchavior would have had on the prior opinion of an optimal Bayesian information processor. Over all experimental conditions, the correlation between SLLR and BLLR was .48, significant at the .01 level.

$O s^{\prime}$ ratings of the actor's attitude favorability were consistent with the probabilistic estimates. The mean ratings in the LI and HI conditions were 3.18 and 2.36 , respectively $(F=6.15, p<.05)$. Also, ratings of the actor's freedom (the sum of $O$ 's responses to the questions asking about the actor's freedom to turn down the experimenter's request and to express his true opinion) were higher in the LI condition (7.16) than in the $\mathrm{HI}$ condition $(5.28)(F=14.11, p<.005)$.

\section{DISCUSSION}

In this study, the inference of an actor's attitude from his behavior in a forced compliance situation was regarded as a process of revision in opinion in light of new information. Bayes' theorem was used as a model of this attribution process. According to the model, $O$ 's initial knowledge about an actor with regard to a given set of traits can be expressed in terms of a prior probability distribution over the traits. Furthermore, $O$ 's perception of an actor in a situation also includes a set of conditional probabilities of the various possible behaviors given the various traits considered. For two traits (or subsets of traits), it is assumed that the prior trait probabilities give rise to prior odds, i.e., the ratio of the two trait probabilities, and that the set of conditional behavior probabilities give rise to a likelihood ratio for each behavior, i.e., a ratio of the probability of the behavior under one trait to the probability of the behavior under the other trait. The model states that the amount of revision from prior to posterior odds (or their logarithms) justified by the observation of a behavior is specified by the likelihood ratio (or its $\operatorname{logarithm}$ ) associated with the behavior, i.e., its diagnostic value.

The significance of the model is mainly that it identifies dimensions (the input components into Bayes' theorem) in terms of which the perceived stochastic structures of a situation can be analyzed. These dimensions were used in the present study for the analysis of the $O \mathrm{~s}^{\prime}$ perception of the forced compliance situation. The attributional analysis of the forced compliance situation (Kelley, 1967) served as a general framework for the simulation of Os' perceptions along these dimensions. Messick's (1971) model of asymmetric certainty (which parallels Kelley's analysis) was taken as a first approximation to $O$ 's perception of the HI condition. Hence, compliance was expected to be more probable and less diagnostic than refusal. The hypotheses about the LI condition were derived from the assumption that $O$ s perceive this situation as allowing actors to behave in manners which express their attitudes. Accordingly, 
since the attitude which is congruous with compliance was assumed to have low prior probability, the probability of compliance was expected to be lower than that of refusal. Also, both compliance and refusal were expected to have high diagnostic values.

The results clearly supported the expectations about the HI condition. It seems then, that the asymmetric certainty model is a useful approximation to $O s^{\prime}$ perception of this situation. However, the hypothesized effects under the LI condition were not obtained. The results indicate that compliance is at least as probable and less diagnostic than refusal. In terms of Kelley's analysis, Os did not seem to expect that only few actors would comply and did not believe that only those who hold the corresponding attitude would comply. Os seemed to expect that many actors would comply and that a considerable proportion of those who possess the incongruous attitude would comply. In principle, it should be possible to create a LI condition where only the few actors possessing the congruous attitude are expected to comply. The results of the present study, however, raise doubts whether the LI condition in the typical forced compliance experiment actually does produce such expectations in Os. Stated otherwise, it may be difficult to devise a situation in which, on one hand, all actors, regardless of their attitudes, actually comply, but in which, on the other hand, Os expect only those possessing a particular attitude to comply.

Most hypotheses which are restricted to comparisons between the inducement conditions were supported. Thus, the perceived probability of compliance was higher in the HI than in the LI condition. To use Kelley's terminology, Os entertained the quite unwarranted assumption of differential rates of compliance in the two conditions. Furthermore, as expected, compliance was considered as more diagnostic in the LI than in the HI condition. However, the parallel tendency to perceive refusal as more diagnostic in the HI than in the LI condition was not unequivocally demonstrated. In sum, in "reality" the diagnostic values of compliance in the LI and HI conditions to not differ-in both they are very small (nearly all actors comply in both conditional). Os therefore overestimated the diagnostic value of compliance, or underestimated the external pressures, in the LI condition in particular. Os thus also exaggerated the difference between the two conditions. They did so, however, to a smaller extent than that expected under current attributional analyses of $\mathrm{Os}^{\prime}$ perception of the forced compliance situation.

Coming to the attributions made after observing compliance, Os were more confident in inferring the corresponding attitude in the LI than in the HI condition. This was shown in terms of posterior trait probabilities as well as in terms of subjective log likelihood ratios, i.e.. the actual 
diagnostic impact of observed behavior on the initial opinion. It should be noted that in both conditions, in spite of observing compliance, Os still believed that the actor is less likely to hold the corresponding attitude than the other attitude. The relevance of the input components and of the Bayesian rule for their combination to the attribution process was demonstrated by the significant correlations between Bayes' theorem prescriptions and $O s^{\prime}$ inferences.

Finally, the attribution literature places a strong emphasis on the role of overall prior behavior probabilities in trait inference. In this study, the concept of diagnostic value of behavior was emphasizcd. Onc may question the value of such a concept since in the present study behavior probabilities were related (inversely) to behavior's diagnostic values and to posterior trait probabilitics. It should be clear, however, that, mathematically at least, behavior's diagnostic value and overall probability are independent. Behavior probability can be, say, high and its diagnosticity can be either high or low. An experimental manipulation of these two factors in an orthogonal fashion is suggested by this analysis as an interesting possibility for future research.

\section{REFERENCES}

AJzen, I. Attribution of a disposition to an actor: effect of perceived decision freedom and behavioral utilities. Journal of Personality and Social Psychology, 1971, 18, 149-156.

BEM, D. An experimental analysis of self persuasion. Joumal of Experimental and Social Psychology, 1965, 1, 199-218.

BEM, D. J. Self perception theory. In L. Berkowitz (Ed.), Advances in experimental social psychology, Vol. 6. New York: Academic Press, 1972, pp. 1-62.

CoHen, A. R. An experiment on small rewards for discrepant compliance and attitude change. In J. W. Brehm and A. R. Cohen Explorations in cognitive dissonance. New York: Wiley, 1962, pp. 73-78.

Edwands, W., Lindian, $H_{\text {, }}$ \& Prillips, L. D. Emerging technologies for decision making. In New directions in psychology, Vol. 11. New York: Holt, 1965.

Festinger, L., \& Carcsmith, J. M. Cognitive consequences of forced compliance. Journal of Abnormal and Social Psychology, 1959, 58, 203-211.

HEIDER, F. The psychology of interpersonal relations. New York: Wiley, 1958.

Helmreich, R., \& Collins, B. E. Studies in forced compliance: Commitment and magnitude of inducement to comply as determinants of opinion change. Journal of Personality and Social Psychology, 1968, 10, 75-81.

Jones, E. E., \& Davis, K. E. From acts to dispositions. In L. Berkowitz (Ed.), Advances in experimental social psychology, Vol. 2. New York: Academic Press, 1965, pp. 219-266.

Jones, E. E., Davis, K. E., \& Gercen, K. J. Role playing variations and their informational value for person perception. Joumal of Abnormal and Social Psychology, 1961, 63, 301-310.

Jones, E. E., \& Gerard, H. B. Foundations of social psychology. New York: Wiley, 1967. 
KelLEy, H. H. Attribution theory in social psychology. In D. Levine (Ed.), Nebraska symposium on motivation. Lincoln: University of Nebraska Press, 1967.

Kelly, H. H. Attribution in social interaction. General Learning Press, 1971.

Messick, D. M. Logical aspects of social inference. Paper presented at the Third Research Conference on Subjective Probability, Utility, and Decision Making. Brunel University, Uxbridge, England, 1971.

Peterson, C. R., \& Miller, A. J. Sensitivity of subjective probability revision. Journal of Experimental Psychology, 1965, 70, 117-121.

Phillips, L., \& Edwards, W. Conservalism in a simple probability inference task. Journal of Experimental Psychology, 1966, 72, 346-354.

Rotren, J. B. Generalized expectancies for internal versus external control of reinforcement. Psychological Monographs, 1966, 80 (Whole No. 609).

STEINER, I. D. Perceived freedom. In L. Berkowitz (Ed.), Advances in experimental social psychology, Vol. 5. New York: Academic Press, 1970, pp. 187-248.

Trope, Y. Changes in perceived freedom and attitude as a result of observing oneself engage in counter-attitudinal behavior. Unpublished manuscript. The University of Michigan, Ann Arbor, 1971.

(Received November 10, 1972) 